\title{
Efeitos Heterogêneos do Capital Humano nos Salários Uma Análise Quantílica na Região Sul do Brasil
}

http://dx.doi.org/10.21527/2237-6453.2020.51.147-167

Recebido em: 1 ㅇ/6/2018

Aceito em: 6/9/2019

Paulo Sergio Ceretta, ${ }^{1}$ Kalu Soraia Schwaab ${ }^{2}$

\begin{abstract}
RESUMO
Partindo-se da importância econômica e administrativa da temática salarial, aliada à Teoria do Capital Humano, o objetivo principal deste estudo é mensurar os efeitos do capital humano sobre os salários do trabalhador na Região Sul do Brasil. Assim, tem-se como proposta estimar os impactos do capital humano na remuneração para diferentes quantis de renda, identificando, ainda, fatores discriminatórios. Para isso, utilizam-se os microdados da Pesquisa Nacional por Amostra de Domicílios Contínua (Pnadc) de 2019. A amostra é composta por 41.014 indivíduos, adota-se a correção do viés de seletividade de Heckman (1979), tendo como técnicas de análise regressões quantílicas com variáveis dummies e a decomposição salarial de Oaxaca (1973) e Blinder (1973). Os principais resultados indicam que os impactos do capital humano são heterogêneos e ascendentes nos quantis de renda, sugerindo evidências para o efeito glass ceiling para as mulheres e para não brancos no Sul do Brasil. Tangente à suposição de fatores discriminatórios, foram encontrados impactos negativos para as dummies de gênero e de raça/cor, sendo os superiores referentes ao gênero. A contribuição teórica diz respeito à área de gestão de pessoas, adicionando resultados empíricos a questões de políticas salariais. A contribuição prática refere-se aos trabalhadores quanto aos retornos de se investir em educação. Espera-se ainda, que este estudo contribuía para elaboração de políticas públicas buscando igualdade salarial no sul do Brasil.
\end{abstract}

Palavras-chave: Capital humano. Salários. Discriminação.

HETEROGENEOUS EFFECTS OF HUMAN CAPITAL ON WAGES: A QUANTILE ANALYSIS IN THE SOUTHERN REGION OF BRAZIL

\begin{abstract}
Based on the economic and administrative importance of the salary theme, allied to the Human Capital Theory, the main objective of this study is to measure the effects of human capital on workers' wages in southern Brazil. Thus, it is proposed to estimate the impacts of human capital on remuneration for different income quantiles in the southern region of Brazil, while also identifying discriminatory factors. For this, the microdata of the National Survey of Continuous Household Sample (Pnadc) of 2019 are used. The sample consists of 41,014 individuals, adopting the correction of the selectivity bias of Heckman (1979), having as analysis techniques quantile regressions with dummies variables and the Oaxaca (1973) and Blinder (1973) wage breakdown. The main results indicate that the impacts of human capital are heterogeneous and upward in income quantiles, suggesting evidence for the glass ceiling effect for women and nonwhites in southern Brazil. Concerning the assumption of discriminatory factors, negative impacts were found for the gender and race dummies, being the superior ones related to gender. The theoretical contribution to the area of people management, adding empirical results to wage policy issues. The practical contribution refers to workers regarding the returns on investing in education. It is also expected that this study contributed to the elaboration of public policies seeking wage equality in southern Brazil.
\end{abstract}

Keywords: Human capital. Wage. Discrimination.

\footnotetext{
${ }^{1}$ Doutor em Engenharia de Produção pela Universidade Federal de Santa Catarina (UFSC). Professor da Universidade Federal de Santa Maria (UFSM).ceretta10@gmail.com

2 Mestre em Gestão de Organizações Públicas pela Universidade Federal de Santa Maria (UFSM). Doutoranda em Administração na Universidade Federal de Santa Maria (UFSM). kaluschwaab@gmail.com
} 
A análise do mercado de trabalho e dos diferenciais salariais são temas de estudo que cada vez mais adquirem relevância pela importância econômica, administrativa e pelo impacto que tem nos níveis de bem-estar social. Nos últimos anos, vários estudos que enfatizam a relação analítica existente entre os salários e a dotação do capital humano têm se proliferado (LLAMAS; LÓPEZ, 2012; ALEJO; GABRIELLI; SOSA-ESCUDERO, 2014; AGRAWAL, 2014; ASSIS; ALVES, 2014; GUIMARÃES; SILVA, 2016; SCHWAAB; CERETTA; DUTRA, 2017; GOMES; SOUZA, 2018). As pesquisas sobre o assunto permitem avaliar dois aspectos fundamentais: os retornos da educação e as diferenças nos salários dos trabalhadores de acordo com o nível de escolaridade e outros atributos sociodemográficos. Ademais, os estudos nessa temática reforçam a reflexão sobre a estrutura salarial no campo da economia do trabalho e são enquadrados na perspectiva do trabalho pela Teoria do Capital Humano (TCH) de Becker (1964) e Schultz (1967).

Além dos fatores econômicos e de capital humano mencionados, existem fatores sociais e culturais que determinam a produtividade e a remuneração de cada indivíduo, as quais explicam as desigualdades salariais. Esses outros fatores estão resumidos na teoria da segmentação (DOERINGER; PIORE, 1970), na teoria da economia da discriminação (BECKER, 1971) e na teoria da discriminação estatística (PHELPS, 1972). Ademais, outras questões devem ser consideradas para a análise: conforme ressaltam Coelho e Corseuil (2002), a região na qual estão inseridos os trabalhadores é fator relevante, uma vez que economias mais desenvolvidas tendem a remunerar melhor.

O Brasil é marcado por diferenças regionais, tanto econômicas quanto sociais. A Região Sul do país destaca-se por apresentar um dos melhores indicadores econômicos e sociais com relação ao restante do Brasil. A Região Sul é a segunda maior em participação na composição do Produto Interno Bruto (PIB) nacional, tendo contribuído com 16,8\% no ano de 2015 (IBGE, 2017b). Destaca-se a Região Sul como a que tem os Estados mais parecidos economicamente entre todas as grandes regiões geográficas, sendo Estados relativamente industrializados e que contam, também, com uma agropecuária relevante (IBGE, 2017b). A referida região é composta pelos Estados do Paraná (PR), Santa Catarina (SC) e Rio Grande do Sul (RS), os quais se caracterizam por possuir alto Índice de Desenvolvimento Humano (IDH). Enquanto o Brasil detém um IDH de 0,761, os Estados do Sul apresentam melhores indicadores nesse sentido, obtendo IDH no PR 0,790; em SC 0,816 e no RS 0,778 (PNUD, 2015). Referente à demografia, a Região Sul possui aproximadamente 29 milhões de habitantes, os quais representam em torno de $14 \%$ da população brasileira.

Os estudos empíricos realizados no Brasil confirmam a existência de diferenciais salariais no mercado de trabalho entre gêneros, assim como entre raças, tanto para o país como para suas regiões (CACCIAMALI; HIRATA, 2005; CACCIAMALI; TATEI; ROSALINO, 2009; CUGINI et al., 2014; SOUZA; GOMES, 2015; PEREIRA; OLIVEIRA, 2016; GOMES; SOUZA; 2018). A Região Sul brasileira revela significativos diferenciais salariais comparados à média nacional, no entanto considera-se a existência de uma lacuna nas pesquisas acerca das diferenças salariais por diferentes quantis de renda. Observa-se que, identificadas as diferenças salariais por quantis de renda na região, seus resultados serão mais detalhados, possibilitando, assim, que intervenções advindas de políticas públicas direcionadas ao mercado de trabalho tornem-se mais eficazes. Diante disso, este estudo tem por objetivo principal mensurar os efeitos do capital humano sobre os 
salários do trabalhador na Região Sul do Brasil. Assim, tem-se como proposta estimar os impactos do capital humano na remuneração para diferentes quantis de renda, identificando, ainda, fatores discriminatórios.

Este artigo está organizado em quatro seções, além desta breve introdução. $\mathrm{Na}$ segunda, apresenta-se o referencial teórico utilizado como subsídio para o estudo, que aborda de forma sucinta os pressupostos teóricos e empíricos, além de questões sobre discriminação de gênero e de raça encontrados em estudos anteriores. Na terceira seção expõem-se os dados, variáveis, estatística descritiva e método adotados. Na quarta são apresentados e discutidos os resultados do estudo. Na quinta e última seção realizam-se as considerações finais.

\section{REFERENCIAL TEÓRICO}

Para a análise dos determinantes de renda da população da Região Sul do Brasil é necessário estimar a equação de rendimentos do trabalho destes indivíduos. Desta forma, recorre-se à Teoria do Capital Humano $(\mathrm{TCH})$, inicialmente difundida pelos economistas Becker (1964) e Schultz (1967). De acordo com a TCH, os salários dos indivíduos são retornos obtidos por investimentos em educação, treinamento, experiência, além de outros fatores. A teoria pressupõe que ao investir nesses aspectos citados, o indivíduo melhora o seu capital humano, e assim a sua produtividade marginal, aumentando o valor esperado de seu trabalho no mercado.

Baseado na TCH e considerando um contexto empírico compatível com os modelos formais da teoria econômica, Mincer (1974) propõe uma equação para analisar a estrutura dos salários e compreender a desigualdade de renda. Essa equação, conhecida por equação minceriana, considera a influência da escolaridade formal e da experiência na renda dos indivíduos. A referida equação pode ser expressa conforme [1].

$$
\ln [w(e, x)]=\alpha+\beta_{1} e_{i}+\beta_{2} x_{i}+\beta_{3} \mathrm{x}_{\mathrm{i}}^{2}+\mu
$$

Em [1], $\ln [w(e, x)]$ é o logaritmo natural da renda ou salário $w$ do indivíduo; para o nível escolar $e$, medido em anos de estudo; e idade $x$, considerada uma proxy para experiência; $\alpha$ é uma constante, $\beta$ é o vetor de parâmetros associados ao vetor das variáveis explicativas, além do termo de erro estocástico, $\mu$, que contém características não observáveis.

As conjeturas sobre a equação [1] são de que os anos adicionais de escolaridade e idade proporcionam impacto positivo sobre a renda, ou seja, os coeficientes $\beta_{1}$ e $\beta_{2}$ são maiores do que zero. Esses aumentos, entretanto, causados pela ampliação da idade estariam sujeitos a retornos decrescentes, dessa forma é esperado que o coeficiente $\beta_{3}$ seja negativo. Assim, utiliza-se a idade juntamente à idade ao quadrado para expandir o modelo, pois segundo Mincer (1974), o termo de escolaridade linear deve ser aumentado por um termo não linear, côncavo, que reflita características de experiência, como a idade.

A TCH presume que os investimentos em capital humano concentram-se em idades mais jovens, mas continuam a uma taxa decrescente durante a maior parte da vida profissional de uma pessoa (BECKER, 1964; MINCER, 1974). A curva de ganhos individuais é intrinsecamente um fenômeno de idade; isso reflete as mudanças de laborio- 
sidade devido à maturação biológica e psicológica, nivelando-se antecipadamente e declinando no tempo por causa do decaimento do vigor físico e intelectual (MINCER, 1974). O perfil de ganhos de vida típico (logarítmico) é, portanto, côncavo. Os perfis de ganhos diferem por ocupação, sexo e cor de formas sistemáticas não atribuíveis aos fenômenos do envelhecimento (MINCER, 1974).

Os estudos sobre os determinantes salariais destacam a escolaridade como um dos principais determinantes (MINCER, 1974; LEITE, 2005; SALARDI, 2014). Ademais, relativo à renda, são abordados na literatura questões sobre desigualdade e diferenças salariais, porventura, algumas de viés discriminatório. Encontrando-se estudos identificando diferenças salariais decorrentes de discriminação racial e de gênero (OAXACA, 1973; OAXACA; RANSOM, 1994; COUCH; DALY, 2002; FRYER, 2010; LANG; LEHMANN; YEON, 2012; SCHWAAB; CERETTA; DUTRA, 2017).

Nos estudos de gênero, o termo gênero é usado para se referir às construções sociais e culturais de masculinidades e feminilidades (BEAUVOIR, 2009). No contexto social, gênero explicitamente exclui referências para as diferenças biológicas e foca nas diferenças culturais, considerando-o como uma aprendizagem social e cultural.

A discriminação pela opção sexual, cor de pele, gênero, religião ou classe social é tema polêmico em âmbito mundial, principalmente no que diz respeito ao plano do mercado de trabalho. Fato esse que induziu muitos países à criação de prerrogativas legais para amparar tais situações. Por exemplo, no Brasil, a Constituição Federal estabelece a igualdade entre os gêneros, em seu artigo 5: "I - homens e mulheres são iguais em direitos e obrigações" (BRASIL, 1988). Tem-se ainda no Brasil a legislação que define os crimes resultantes de preconceito de raça ou de cor (BRASIL, 1989), e a lei antidiscriminação contra origem, raça, cor, estado civil, situação familiar, idade e sexo - Lei Federal n. 9.029/95. Pode-se ainda destacar recentes leis específicas quanto a salários em outros países, como na Islândia e em Portugal, que criaram uma lei que multa empresas que pagam salários menores para mulheres (WORLD..., 2018).

Os discriminantes raciais e de gênero no âmbito do mercado de trabalho têm sido estudados em âmbito mundial (OAXACA, 1973; OAXACA; RANSOM, 1994; COUCH; DALY, 2002; FRYER, 2010; LANG; LEHMANN; YEON, 2012). Referente à discriminação de gênero, esse não é um tema novo, pelo contrário, vem sendo estudado há cerca de meio século por pesquisadores ao redor do mundo, porém discussões continuam a ocorrer buscando aprofundamentos (BECKER, 1971; OAXACA; RANSON, 1994; NEUMARK, 1988; ALTONJI; BLANK, 1999; LIPS, 2013; SALARDI, 2014; LEUZE; STRAUSS, 2016; ADNAN; MIAARI, 2018; HARA, 2018; JUNG; CHOE; OAXACA, 2018).

Quanto à temática sobre diferenciais salariais por gênero, destacam-se o estudo seminal de Oaxaca (1973), que estimou a extensão média da discriminação contra as trabalhadoras nos Estados Unidos e forneceu uma avaliação quantitativa das fontes de diferenciais salariais entre homens e mulheres. Como resultado, o autor encontrou um diferencial grande como em outros estudos (SANBORN, 1964; COHEN, 1971; FUCHS, 1971), e destacou que a remuneração desigual por trabalho igual não é responsável por muito do diferencial salarial entre homens e mulheres. Em vez disso, é a concentração de mulheres em empregos de menor remuneração que produz diferenciais tão grandes. Os resultados de Oaxaca (1973), porém, sugerem que uma proporção substancial do diferencial salarial entre homens e mulheres é atribuível aos efeitos da discriminação. 
Com relação aos estudos sobre diferenciais salariais por gênero e raciais, destacam-se dois termos relevantes na literatura: glass ceiling e sticky floor. O efeito glass ceiling, ou teto de vidro, compreende que os diferenciais de rendimentos são elevados no topo da distribuição. Ao contrário, o efeito sticky floor, ou chão pegajoso, abrange os diferenciais de rendimentos na parte inferior da distribuição (CHI; LI, 2008). A literatura internacional aponta a existência de um hiato salarial de gênero maior na parte inferior da distribuição, isto é, maior presença do efeito sticky floor (CHI; LI; YU, 2007; CHI; LI, 2008; ADIREKSOMBAT; ZHENG; SAKELLARIOU, 2010; BHORAT; GOGA, 2013).

$O$ mercado de trabalho brasileiro vem passando por transformações. A desigualdade entre gêneros no trabalho, por exemplo, vem diminuindo, com uma aparente meIhoria para as mulheres. O diferencial médio entre homens e mulheres que era de $27 \%$ em 2012 sofreu uma redução, passando para 23\% em 2017 (IBGE, 2017b). Destaca-se que, na Região Sul os diferenciais são historicamente maiores do que a média nacional, por exemplo, nesse mesmo período, o percentual entre gêneros variou de $28 \%$ para 25\% (IBGE, 2017b).

Essas temáticas têm sido abordadas também no Brasil (BARROS et al. 2001; LEITE, 2005; SALARDI, 2014; SCHWAAB; CERETTA; DUTRA, 2017). Barros et al. (2001) realizam uma discussão sobre a inserção no mercado de trabalho. Os resultados dos referidos autores revelam que a maior inserção do gênero feminino no mercado de trabalho encontrada tem ocasionado efeitos bastante limitados sobre o bem-estar familiar. Os autores justificam esse resultado devido às oportunidades de emprego das mulheres não serem semelhantes às dos homens.

Leite (2005) em seus resultados alude que as diferenças de capital humano anteriores ao mercado de trabalho são as principais responsáveis pela diferença salarial entre trabalhadores brasileiros. As diferenças salariais entre raças, normalmente atribuídas à discriminação, segundo o autor, podem ser explicadas por persistentes desigualdades educacionais. Destaca o autor, ainda, que a desigualdade no acesso à educação de qualidade é fator contributivo para situações de pobreza entre a população negra. Segundo Leite (2005), a inserção dos negros no mercado de trabalho é problemática devido ao seu baixo nível educacional - capital humano - que vem a ser refletido em seus salários.

Salardi (2014), por sua vez, estudou a evolução da segregação ocupacional de gênero e racial no Brasil, considerando o período de 1987 a 2006. Para tanto, utilizou dados da Pesquisa Nacional por Amostra de Domicílios (Pnad). A autora utiliza o método de Duncan e Duncan (1955). Os principais resultados desse estudo é que a segregação de gênero é sempre maior que a segregação racial no período analisado, mas destaca que a segregação de raça tem sido mais persistente ao longo do tempo. Outro aspecto é que a segregação diminuiu em maior nível no mercado de trabalho formal do que no informal, e que a redução da segregação racial ocorreu entre o gênero feminino, permanecendo constante entre o gênero masculino.

No estudo de Schwaab, Ceretta e Dutra (2017), os autores analisam os efeitos da educação na renda da população brasileira a partir da Pnad de 2014 com regressões Ordinary Least Squares (OLS), encontrando resultados para cada região do país. Nesse estudo a renda média da Região Sul é de $R \$ 1.920,53$, constando dentre as regiões brasileiras como a segunda maior com relação à renda. Foi observado para essa região que um ano a mais de escolaridade tem um retorno de aproximadamente $\mathrm{R} \$ 210,00$ na ren- 
da dos indivíduos. O retorno observado para um ano a mais de idade foi de cerca de $\mathrm{R} \$$ 40,00 a mais na renda. Os referidos autores identificaram em seu modelo, por meio de variáveis dummies, que características raciais e de gênero também interferem na renda dos brasileiros. Para os indivíduos da Região Sul autodeclarados de cor/raça preta e parda foram identificadas reduções nos rendimentos de aproximadamente $R \$ 360,00$ para pretos e $\mathrm{R} \$ 260,00$ para pardos quando comparados com indivíduos da cor/raça branca. Com relação ao gênero, a variável dummy, que identifica o gênero masculino, percebe um retorno positivo de cerca $\mathrm{R} \$ 800,00$ a mais na renda por ser homem. Esses mesmos autores ainda identificaram que trabalhadores do setor público na Região Sul recebem cerca de $\mathrm{R} \$ 660,00$ a mais do que os do setor privado.

Diferenças salariais entre os setores público e privado também são pesquisados no Brasil (MEDEIROS; SOUZA, 2014; BRASIL; MACEDO, 2017). Medeiros e Souza (2014), por meio de uma decomposição fatorial do Coeficiente de Gini, mediram a contribuição para a desigualdade dos fluxos de renda monetária do Estado, com dados da Pesquisa de Orçamentos Familiares (POF) brasileira 2008-2009. Os resultados desse estudo indicam que o Estado contribui diretamente para uma parcela muito grande da desigualdade. Os referidos autores apontam que fatores associados ao trabalho no setor público, como salários e pensões, são muito concentrados e regressivos. Esse estudo de Medeiros e Souza (2014) obteve como um dos principais resultados que a diferença existente entre os salários dos setores público e privado seria responsável por cerca de $75 \%$ do Coeficiente de Gini no Brasil.

Já Brasil e Macedo (2017) investigaram a influência do diferencial de rendimentos dos trabalhadores dos setores público e privado e o valor de aposentadorias e pensões superiores ao teto do Regime Geral de Previdência Social (RGPS) sobre a desigualdade de renda. Os autores utilizam o método de decomposição do Índice de Gini para a construção de distribuições hipotéticas, aplicado nos dados da Pnad no período entre 2004 e 2013. Os resultados de Brasil e Macedo (2017) apontam que a elevada remuneração dos funcionários públicos foi responsável, em média, por 2,84\% da desigualdade de renda no período. Os autores afirmam que, por meio da decomposição, também foi possível verificar que as parcelas de rendimento atreladas a empregados com maior qualificação são consideravelmente mais regressivas do que empregados com nível inferior de escolaridade. Os referidos autores constatam que a lacuna público-privada apresentou uma tendência crescente ao longo do período investigado, motivada principalmente pelo crescimento médio real superior dos rendimentos do funcionalismo público em comparação ao privado.

Esse referencial teórico proporciona um breve panorama na temática sobre questões salariais, abordando de forma sucinta os pressupostos teóricos e empíricos, além de questões sobre discriminação de gênero e de raça encontrados em estudos anteriores.

\section{METODOLOGIA}

Os dados utilizados neste estudo fazem parte dos microdados da Pesquisa Nacional por Amostra de Domicílios Contínua (Pnadc), referente ao primeiro trimestre de 2019, e encontram-se disponíveis no Portal do Instituto Brasileiro de Geografia e Estatística (IBGE). O banco de dados da PNADC contém informações sobre características socioeconômicas, especialmente em relação ao emprego e renda dos trabalhadores brasileiros. 
Em função do objetivo da pesquisa selecionaram-se apenas pessoas que residem na Região Sul brasileira, que declararam ter trabalhado pelo menos 1 hora na semana de referência da pesquisa, com renda positiva e com idade entre 14 e 65 anos. 0 critério adotado para seleção da idade envolve conceitos de população potencialmente ativa, sendo adotada a idade mínima de 14 anos por ser a permitida por lei para o trabalho no Brasil (BRASIL, 2000). Desta forma, compõem a amostra 41.014 pessoas.

Neste estudo optou-se por incluir somente os indivíduos que declararam ter trabalhado pelo menos 1 hora na semana de referência e com renda positiva, e dessa forma excluíram-se os demais (desempregados e inativos). Para corrigir problemas decorrentes da seleção não aleatória da amostra, aplica-se o Tobit II, modelo desenvolvido por Heckman (1979). O procedimento de Heckman é amplamente utilizado na literatura para correção de viés de seleção amostral (AGRAWAL, 2014; ASSIS, ALVES, 2014; GUIMARÃES, SILVA, 2016).

Na Tabela 1 apresentam-se a média e o desvio padrão da renda mensal, estudo e idade, segmentados por raça/cor, gênero ${ }^{3}$ e setor de atuação, assim como a frequência amostral para cada segmento.

Tabela 1 - Estatística descritiva da amostra na Região Sul do Brasil no 10 trimestre de 2019: Média (desvio padrão)

\begin{tabular}{|c|c|c|c|c|c|c|}
\hline Carac & erísticas & Renda & Estudo & Idade & Observações & Percentual \\
\hline \multirow{4}{*}{ Raça/cor } & Branca & $2.568,58$ & 11,24 & 38,17 & \multirow{2}{*}{31.528} & \multirow{2}{*}{$77 \%$} \\
\hline & & $(3.587,90)$ & (3.80) & $(12,47)$ & & \\
\hline & \multirow{2}{*}{ Não branca } & $1.786,16$ & 9.71 & 39,55 & \multirow{2}{*}{9.486} & \multirow{2}{*}{$23 \%$} \\
\hline & & $(1.830,68)$ & $(3,85)$ & $(12,46)$ & & \\
\hline \multirow{4}{*}{ Gênero } & Masculino & $2.680,16$ & 10,36 & 39,59 & \multirow{2}{*}{23.440} & \multirow{2}{*}{$57 \%$} \\
\hline & & $(3.901,37)$ & $(3,86)$ & $(12,74)$ & & \\
\hline & \multirow[t]{2}{*}{ Feminino } & $1.997,42$ & 11,59 & 38,75 & \multirow{2}{*}{17.574} & \multirow{2}{*}{$43 \%$} \\
\hline & & $(2.142,44)$ & $(3,76)$ & $(12,10)$ & & \\
\hline \multirow{4}{*}{ Setor } & Privado & $2.218,88$ & 10,60 & 38,88 & \multirow{2}{*}{37.660} & \multirow{2}{*}{$92 \%$} \\
\hline & & $(3.125,50)$ & $(3,82)$ & $(12,58)$ & & \\
\hline & Público & $4.282,30$ & 14,06 & 43,18 & \multirow{2}{*}{3.354} & \multirow{2}{*}{$8 \%$} \\
\hline & & $(4.269,05)$ & $(2,88)$ & $(10,54)$ & & \\
\hline
\end{tabular}

Fonte: Elaborado pelos autores (2019).

Nota: Apresentam-se as médias para as variáveis: renda, valores em moeda real; estudo, medido em anos de estudo; e idade, em anos. Desvio padrão entre parênteses.

Observando a Tabela 1, nota-se que nos segmentos amostrais de maiores rendimentos médios ocorrem as maiores médias de escolaridade, indicando evidências para a Teoria do Capital Humano, com exceção ao segmento de gênero (BECKER, 1964). Já referente às médias na idade, quanto aos setores e quanto a gênero verificou-se conformidade com a Teoria. Quanto às raças, a branca apresenta a maior média de renda ( $R \$ 2.568,58)$, apresentando também a maior média de estudo $(11,24$ anos). Referente ao gênero, observa-se o contrário, no tocante à escolaridade os homens apresentam as menores médias (10,36 anos de estudo) e os maiores rendimentos médios ( $R \$$

\footnotetext{
${ }^{3}$ Nesta pesquisa o termo gênero refere-se à autodeclaração realizada na pesquisa PNADC quanto ao questionamento número 7: sexo (homem/mulher).
} 
$2.680,16)$, enquanto as mulheres apresentam os maiores níveis educacionais $(11,59$ anos) e os menores rendimentos médios (R\$1.997,42). Quando se observa o setor, o público possui a maior média de renda $(\mathrm{R} \$ 4.282,30)$ da amostra, apresentando também os maiores níveis de escolaridade (14,06 anos) e idade (43,18 anos). Cabe testar se esses diferenciais são significantes e se a TCH tem poder de explicar os diferenciais de renda e quais as suas magnitudes.

Na primeira coluna da Tabela 2 apresentam-se as variáveis dependente e explicativas utilizadas na pesquisa, nas colunas seguintes, a descrição da variável, o sinal esperado do efeito sobre a variável dependente e os autores que foram utilizados para essa referência. Destaca-se como variáveis explicativas da produtividade do trabalhador (logaritmo da renda/hora), o estudo, medido em anos de estudo, a idade como tempo de experiência acumulada ao longo da vida e, utiliza-se a idade ao quadrado, pois de acordo com Mincer (1974), o termo de escolaridade linear deve ser aumentado por um termo não linear. Sendo assim, a relação entre experiência e renda tem o formato côncavo, ou seja, o indivíduo ganha mais por ter mais experiência até certo ponto, depois o rendimento tende a cair com a senilidade.

Tabela 2 - Variáveis dependente e explicativas, sinal esperado e autores utilizados no estudo

\begin{tabular}{|c|c|c|c|}
\hline Variável & Descrição & Sinal esperado & Autor \\
\hline $\begin{array}{l}\text { LnRen- } \\
\text { daHora }\end{array}$ & $\begin{array}{l}\text { Logaritmo natural da } \\
\text { renda/hora do trabalho } \\
\text { principal }\end{array}$ & $\begin{array}{l}\text { Variável de- } \\
\text { pendente }\end{array}$ & Mincer (1974). \\
\hline Estudo & $\begin{array}{l}\text { Anos de estudo do traba- } \\
\text { lhador }\end{array}$ & Positivo (+) & $\begin{array}{l}\text { Becker (1964), Mincer (1974), } \\
\text { Alejo, Gabrielli, e Sosa-Escudero } \\
\text { (2014). }\end{array}$ \\
\hline Idade & $\begin{array}{l}\text { Idade do trabalhador em } \\
\text { anos }\end{array}$ & Positivo (+) & $\begin{array}{l}\text { Becker (1964), Mincer (1974), } \\
\text { Alejo, Gabrielli e Sosa-Escudero } \\
\text { (2014). }\end{array}$ \\
\hline Idade $^{2}$ & Idade $^{2}=(\text { Idade })^{\wedge} 2 / 100$ & Negativo (-) & $\begin{array}{l}\text { Mincer (1974); Llamas e López } \\
\text { (2012). }\end{array}$ \\
\hline
\end{tabular}

Fonte: Elaborado pelos autores (2019).

Algumas variáveis dummies são utilizadas neste estudo e estão apresentadas na Tabela 3. O objetivo dessas variáveis é controlar alguns fatores que, apesar de não serem atributos de capital humano, também afetam a renda do trabalhador (BLINDER, 1973; OAXACA; 1973; MINCER, 1974; COUCH; DALY, 2002; LANG; LEHMANN; YEON, 2012). As variáveis dummies utilizadas são para identificar o gênero (masculino e feminino), a autodeclaração de cor/raça (preta, parda ou branca) e o setor de atuação (público e privado). 
Tabela 3 - Variáveis dummies, descrição e autores utilizados no estudo

\begin{tabular}{lll}
\hline Variável & Descrição & Autores \\
\hline D_Fem & $\begin{array}{l}\text { Dummy igual a } 1 \text { se o trabalhador é } \\
\text { do gênero feminino e 0, caso contrá- } \\
\text { rio. }\end{array}$ & $\begin{array}{l}\text { Sanborn (1964); Cohen (1971); Fuchs } \\
\text { (1971); Oaxaca (1973); Barros, et al. } \\
\text { (2001); Salardi (2014). }\end{array}$ \\
D_Branca* & $\begin{array}{l}\text { Dummy igual a 1 se o trabalhador é } \\
\text { autodeclarado de cor/raça branca e }\end{array}$ & $\begin{array}{l}\text { Couch \& Daly (2002); Lang, Lehmann e } \\
\text { O, caso contrário. }\end{array}$ \\
& $\begin{array}{l}\text { Dummy igual a } 1 \text { se o trabalhador } \\
\text { pertence ao setor público e 0, caso } \\
\text { D_Público }\end{array}$ & $\begin{array}{l}\text { Medeiros e Souza (2014); Brasil e Mace- } \\
\text { do (2017). }\end{array}$ \\
& &
\end{tabular}

Fonte: Elaborado pelos autores (2019).

Nota: ${ }^{*}$ Utiliza-se neste estudo as nomenclaturas de cor/raça de acordo com as nomenclaturas da PNADC (IBGE, 2017a), observando-se que, nesta pesquisa, foram excluídos das análises amarelos e indígenas.

Em grande parte dos estudos sobre determinantes salariais o foco é o interesse em se verificar a magnitude do impacto do capital do humano no diferencial salarial (LEITE, 2005; LLAMAS; LÓPEZ, 2012; SCHWAAB; CERETTA; DUTRA, 2017). As estimativas das funções de renda por meio do Método Ordinary Least Squares (OLS) originam resultados médios, não identificando variações nos impactos quando se tem uma amostra não homogênea, como são os casos de censos ou pesquisas populacionais.

Para a estimativa dos efeitos do capital humano sobre os salários do trabalhador na Região Sul do Brasil adota-se o modelo econométrico de Regressão Quantílica de Koenker e Bassett Jr. (1978), abalizado pela lógica da equação minceriana de salários, que se encontra descrita na revisão teórica (MINCER, 1974). A regressão quantílica permite analisar o rendimento da população do Sul e as variáveis explicativas de forma mais detalhada, pois permite uma visão mais ampla entre a variável dependente e as variáveis explicativas, estimando parâmetros para diversos pontos da distribuição. A diferença dos parâmetros estimados para cada quantil indica as diferentes respostas da variável dependente ao longo da distribuição.

Na regressão quantílica os coeficientes estimados medem a influência das variáveis explicativas sobre a variável dependente condicionadas ao $\theta$-ésimo quantil. Desta forma, será possível determinar a influência das características dos indivíduos na renda para diferentes quantis condicionais. Com a finalidade de verificar se os coeficientes estimados diferem estatisticamente entre os quantis, são aplicados testes Wald para os parâmetros dos nove quantis de cada variável (JOHNSTON; DINARDO, 1996).

Para estimar as diferenças nos retornos em termos de rendimentos para os atributos dos trabalhadores da Região Sul do Brasil em diferentes níveis da distribuição de tal variável, é utilizado o modelo [2]:

$$
\ln [w(e, x)]_{k}=\beta_{0}^{\theta}+\beta_{1}^{\theta} E_{k}+\beta_{2}^{\theta} I_{k}+\beta_{3}^{\theta} I_{k}^{2}+\beta_{4}^{\theta} G_{k}+\beta_{5}^{\theta} R_{1 k}+\beta_{6}^{\theta} R_{2 k}+\beta_{7}^{\theta} S_{k}+\varepsilon_{k}^{\theta}
$$

Em [2], $\beta_{\mathrm{i}}^{\theta}$ são os coeficientes estimados para as variáveis independentes $(i=1, \ldots, 7)$ sobre o logaritmo da renda/hora $\left(\ln [w(e, x)]_{k}\right)$ no quantil $\vartheta ; E$ é a variável discreta que indica a escolaridade do trabalhador, em anos de estudo; I representando a idade do trabalhador como proxy da experiência; G é uma variável variáveis dummy que indica o gênero do trabalhador, assumindo 1 para feminino e 0 , caso contrário; 
$R_{m}(m=1,2)$ são variáveis dummies que indicam a raça do trabalhador, com o grupo base sendo formado por brancos, $R_{1}$ assumindo o valor 1 para pretos e 0 , caso contrário, e $R_{2}$ assumindo o valor 1 para pardos e 0 , caso contrário; $S$ é uma variável dummy que indica o setor de atividade do trabalhador, sendo o grupo base formado pela iniciativa privada e quando $S=1$ identifica indivíduos do setor público; e $\varepsilon_{k}^{\theta}$ representa os resíduos da regressão.

A decomposição de Oaxaca (1973) e Blinder (1973) é uma técnica de análise amplamente utilizada nos estudos sobre diferenciais salariais (AGRAWAL, 2014; ASSIS; ALVES, 2014; GUIMARÃES; SILVA, 2016). A abordagem utilizada neste estudo é do tipo threefold, conforme Jann (2008), divide a média da distribuição dos rendimentos em três componentes: a) efeito composição; b) efeito estrutura salarial e c) efeito interação. No efeito composição, as diferenças observadas devem-se às características observáveis (educação, experiência, etc.) entre grupos; enquanto o efeito estrutura salarial representa as diferenças nos retornos a essas características, ou seja, nos coeficientes remuneratórios. $O$ efeito do termo de interação mede a interação simultânea entre as diferenças no componente efeito composição e as diferenças no efeito estrutura salarial entre os grupos.

\section{RESULTADOS}

Os resultados deste estudo estão demonstrados nas Tabela 4 (Anexo 1), Tabela 5 (Anexo 2) e na Figura 1. São apresentados os resultados das decomposições salariais Oaxaca-Blinder (1973) entre gêneros, raça/cor e setor na Tabela 4. Por meio da decomposição dos diferenciais de renda por gênero $(0,114)$, observa-se que o efeito composição $(-0,108)$ apresenta sinal negativo, reduzindo o gap salarial e que o efeito estrutura salarial $(0,223)$ apresenta sinal positivo, aumentando o gap salarial existente entre homens e mulheres.

O efeito composição é estatisticamente significante a $1 \%$ e contribui com $94,74 \%$ na redução do diferencial de renda entre gêneros. Esse resultado confirma outros estudos, como o de Pereira e Oliveira (2016) no RS, Cugini et al. (2014) no Brasil e Guimarães e Silva (2016) no setor de turismo brasileiro, os quais encontraram sinal negativo para esse efeito. Isso indica que, considerando as características femininas (escolaridade, experiência, etc.), as quais em média são superiores às masculinas (ver Tabela 1), o gap salarial sofre uma redução de $-0,108$, ou seja, de $-11,4 \%$ segundo o coeficiente em exponencial.

O efeito estrutura salarial quantifica a mudança nos salários das mulheres ao aplicar os coeficientes masculinos às variáveis analisadas para as mulheres. O efeito composição é estatisticamente significante a 1\%, representando 195,61\% do gap salarial entre gêneros. Assim, pode-se inferir que grande parte do diferencial de renda entre gêneros decorre de discriminação, dado que os atributos referentes a características pessoais dos indivíduos são mais considerados que as suas dotações de capital humano. O resultado aponta que, se fossem aplicados os coeficientes masculinos às características das mulheres, ou seja, se não houvesse discriminação, as mulheres teriam um aumento salarial médio de $20 \%$. Já o efeito interação, que é o efeito simultâneo de algumas variáveis de composição e estrutura, aumenta o diferencial salarial entre gêneros em apenas $0,88 \%$. 
Ao analisar a decomposição dos diferenciais por raça/cor $(0,256)$, observa-se que o efeito composição $(0,165)$ e o efeito estrutura salarial $(0,134)$ aumentam o gap salarial entre brancos e não brancos, pois ambos os efeitos apresentam sinal positivo. 0 efeito composição contribui com $64,27 \%$ no aumento do hiato salarial entre raças, isto é, se os não brancos tivessem as mesmas características médias dos brancos o hiato de renda entre raças seria menor. Assim, se os não brancos tivessem as dotações dos brancos (educação, experiência, etc.) a diferença do log dos rendimentos entre raças diminuiria em $-0,165$, isto é, em $15,2 \%$. O efeito estrutura salarial representa $52,38 \%$ do gap salarial por hora. $\mathrm{O}$ resultado aponta que, se fossem aplicados os coeficientes dos brancos às características dos não brancos, ou seja, se não houvesse discriminação, os não brancos teriam um aumento salarial de 12,6\%.

Os resultados da decomposição entre raças para Região Sul brasileira indicam que o gap salarial entre raças é explicado pelos dois efeitos, sendo que a maior parte do diferencial médio do salário/hora é devido a diferenças no efeito composição, isto é, diferenças em capital humano, como anos de estudo e experiência. Isso revela a importância da igualdade na promoção de uma educação de qualidade para equalizar as oportunidades. Quando comparamos o diferencial do salário/hora por gênero e por raça, nota-se que o hiato salarial por gênero $(0,114)$ é menor do que o diferencial por raça/cor $(0,256)$ no Sul do Brasil, contrariando os resultados a nível de Brasil de Salardi (2014). Quando, porém, se observa as decomposições dos diferenciais, verifica-se a incidência de uma maior discriminação de gênero $(195,61 \%)$ do que de raça $(52,38 \%)$ na composição dos diferenciais, assim como, em seus efeitos redutores nos salários, de $20 \%$ (mulheres) e 12,6\% (não brancos).

Ao analisar a decomposição dos diferenciais salariais por setor $(0,686)$, observa-se que o efeito composição $(0,548)$ e o efeito estrutura $(0,333)$ aumentam o gap salarial entre trabalhadores dos setores público e privado, pois ambos apresentam sinal positivo. O efeito composição contribui com $79,88 \%$ no aumento do hiato salarial entre esfera pública e privada. Esse resultado indica que se os trabalhadores do setor privado tivessem as mesmas características médias dos trabalhadores públicos o hiato de renda entre esses setores seria menor, percebendo os trabalhadores privados um aumento salarial de $42,2 \%$. Assim, grande parte do diferencial do salário/hora desses setores é explicado por diferenças em dotações individuais, como educação e experiência, ou seja, por características de capital humano dos trabalhadores.

Já o efeito estrutura salarial representa $48,44 \%$ do gap salarial por hora entre os setores. Esse resultado revela que existe uma parcela do hiato salarial entre trabalhadores do setor público e privado vinculada a diferenças nos coeficientes remuneratórios. Deste modo, mesmo que os trabalhadores privados possuam as mesmas dotações (escolaridade, idade, experiência, etc.) dos trabalhadores públicos, ainda serão remunerados de forma diferente. Se a diferença no efeito estrutura salarial fosse anulado, os trabalhadores privados receberiam um aumento de $28,3 \%$.

$\mathrm{Na}$ Tabela 5 são apresentados os resultados da regressão OLS com correção do viés de seletividade de Heckman (1979) e das regressões quantílicas para nove quantis condicionais de renda $(0,1$ até 0,9$)$. Na Figura 1 demonstra-se graficamente o comportamento dos impactos das variáveis sobre a renda em cada quantil $(0,1$ até 0,9$)$ e os coeficientes OLS. 
Conforme é possível observar na Tabela 5, o resultado do coeficiente OLS da variável Estudo tem um efeito positivo de $8,2 \%$ na renda. Enquanto, analisando os coeficientes quantílicos dessa variável, revela-se heterogeneidade nos efeitos, demonstrando que para cada ano adicional de estudo os efeitos são igualmente positivos, porém oscilam entre $6,3 \%$ e 9,5\%. Os resultados quantílicos indicam oscilação decrescente nos coeficientes do primeiro para o segundo quantil, e que a partir do segundo quantil os coeficientes apresentam um comportamento ascendente. Esses resultados indicam que os indivíduos que recebem as menores rendas auferem menores retornos pela aquisição de capital humano. Por outro lado, os indivíduos com renda mais alta recebem uma maior valorização pelos investimentos em educação. Esse resultado merece ser explorado, porém suscita-se estar atrelado aos maiores níveis de escolaridade estarem distribuídos nos quantis de rendas mais altas (PEREIRA; OLIVEIRA, 2016). Por exemplo, observando a estatística descritiva (ver Tabela 1 ) os indivíduos do setor público, que apresentam as maiores médias de renda, apresentam também as maiores médias de escolaridade e idade, estando esses resultados fortemente alinhados à Teoria do Capital Humano.

As variáveis Idade e Idade ao quadrado, que constam no modelo como uma proxy para experiência, não apresentam o mesmo padrão de variação de acordo com os quantis de renda. $O$ impacto da Idade é positivo e varia entre 4,0\% e 6,7\% o acréscimo na renda a cada ano a mais de experiência do indivíduo. Já o impacto da Idade ao quadrado é negativo, conforme aponta a literatura, afirmando ocorrer decréscimo no incremento da renda e produtividade em decorrência da idade avançada (MINCER, 1974).

Os resultados positivos das variáveis Estudo e Idade confirmam os pressupostos da $\mathrm{TCH}$, indicando que investimentos em educação formal e experiência têm retornos incrementais nos salários (BECKER, 1964; SCHULTZ, 1967; MINCER, 1974; SCHWAAB; CERETTA; DUTRA, 2017). Os resultados observados na Tabela 5 indicam que um ano a mais de estudo produz acréscimos na renda média mensal. Esses resultados são análogos aos encontrados previamente nos estudos realizados no Brasil (LEITE, 2005; SALARDI, 2014; SCHWAAB; CERETTA; DUTRA, 2017), tendo esse estudo como contribuição o fato de que os impactos da educação são heterogêneos e ascendentes a partir do segundo quantil de renda para a Região Sul brasileira.

A dummy de gênero, que controla os efeitos do gênero feminino, indica no resultado OLS que os salários das mulheres são em média $24,8 \%$ inferiores aos dos homens. Por sua vez, os resultados quantílicos revelam coeficientes negativos e progressivos ao longo dos quantis, variando os salários femininos entre $15,0 \%$ e $27,5 \%$ a menos do que os masculinos. Observa-se que, nos quantis mais baixos $(0,1$ e 0,2$)$, ocorrem as menores diferenças salariais entre gêneros na Região Sul (-15,0 e 16,7\%), no entanto sendo ainda elevadas. O resultado que merece maior relevância, porém, é que, conforme se eleva a renda, maior é o hiato salarial entre homens e mulheres, chegando à magnitude de aproximadamente $30 \%$, sugerindo a existência do efeito glass ceiling no sul do Brasil. Esse resultado contraria a literatura internacional, a qual encontrou diferenciais de renda entre gêneros maiores na parte inferior da distribuição, indicando o efeito sticky floor (CHI; LI; YU, 2007; CHI; LI, 2008; ADIREKSOMBAT; ZHENG; SAKELLARIOU, 2010; BHORAT; GOGA, 2013), no entanto, salienta-se que no Brasil, segundo o estudo de Salardi (2013), foi encontrado tanto o efeito sticky floor quanto o efeito glass ceiling para as mulheres. 
Os resultados obtidos estão inferiores aos de Barros et al. (2001), que mostraram que a diferença salarial média entre homens e mulheres na mesma ocupação e com a mesma escolaridade era cerca de 50\%, indicando uma redução do gap entre gêneros em quase duas décadas. Os referidos autores verificaram que na grande maioria dos casos por eles estudados os salários masculinos eram superiores aos femininos. Barros et al. (2001) afirmaram que em apenas $5 \%$ dos casos considerados o salário médio feminino apresentou-se mais de $10 \%$ superior ao masculino, ao passo que em $81 \%$ dos casos o oposto ocorreu.

Ser autodeclarado de cor e/ou raça branca capta um impacto positivo em todos os quantis. Os maiores impactos estão nos quantis mais altos, atingindo no quantil 0,9 o coeficiente de 13,3\%. Esse resultado demonstra que nos níveis salariais mais elevados encontram-se as maiores diferenças salariais entre raças, revelando uma maior presença de discriminação, sugerindo a presença do efeito glass ceiling para os não brancos no sul do Brasil. Esse resultado converge com os resultados nacionais (SALARDI, 2013).

As desigualdades salariais de gênero e de raça têm sido observadas ao longo do tempo em muitos países, estando os resultados observados análogos aos de Oaxaca (1973), Fryer (2010) e Salardi (2014). Neste estudo, porém, o que se observa é que entre os rendimentos mais altos encontram-se os maiores diferenciais salariais discriminatórios (gênero e raça). Os estudos de Salardi (2014) indicam que a segregação de gênero no Brasil apresenta-se de maior magnitude que a racial, porém esta tem sido mais persistente ao longo do tempo. A autora enfatiza ainda que a segregação racial é menor em termos absolutos, mas tem ocorrido pouquíssimo avanço ao longo do tempo.

O setor público apresenta coeficientes heterogêneos e positivos, sendo crescentes nos quantis que variam entre $26,2 \%$ e $42,8 \%$. O efeito positivo encontrado pode ser explicado pelas médias observadas na Tabela 1, na qual se percebe maiores níveis de escolaridade e experiência relativos aos indivíduos do funcionalismo público. Destaca-se que conforme a renda condicional aumenta, maior é o hiato salarial entre iniciativa pública e privada. Essas disparidades entre setor público e privado têm sido estudadas, por exemplo, por Brasil e Macedo (2017), os quais evidenciaram que tal disparidade entre público-privado tem crescido, sendo a explicação dada pelo crescimento médio real dos rendimentos do funcionalismo público ter sido superior ao do privado.

Apresenta-se na Figura 1 a representação gráfica do comportamento dos impactos das variáveis sobre a renda em cada quantil $(0,1$ até 0,9$)$ e coeficientes OLS na Região Sul relativos aos dados do 1 을 trimestre de 2019. 
Figura 1 - Comportamento dos impactos das variáveis sobre a renda em cada quantil $(0,10$ até 0,90$)$ e coeficientes da regressão OLS para a Região Sul relativo ao ano de 2019
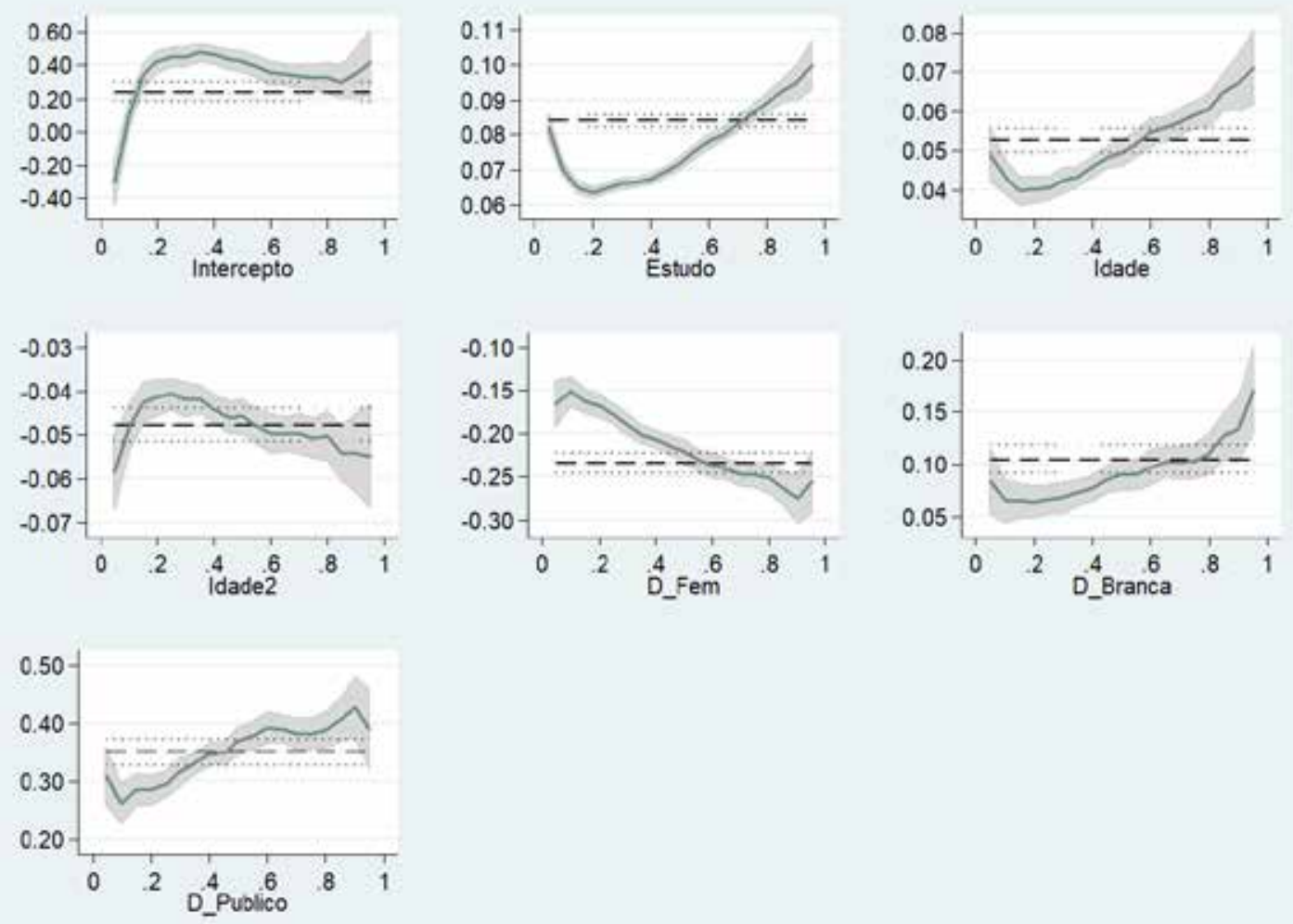

Nota: As linhas (---) representam as estimativas por OLS, (....) representam o intervalo de confiança do OLS, as linhas contínuas (__ r representam as estimativas da regressão quantílica para as variáveis independentes, a parte sombreada representa o intervalo de confiança da regressão quantílica.

Fonte: Elaborado pelos autores (2019).

Os resultados observados confirmam os pressupostos da $\mathrm{TCH}$, com coeficientes positivos para as variáveis estudo e idade, todavia os resultados da regressão quantílica evidenciam existir diferenças no impacto de anos de estudo adicionais, conforme a magnitude da renda. Esse comportamento pode ser claramente observado na Figura 1, quando da análise da variável "estudo", pois conforme o nível de renda eleva-se ao longo dos quantis, os impactos da escolaridade na renda são maiores. É demonstrado um comportamento heterogêneo dessa variável ao longo dos quantis, com os maiores retornos para escolaridade sendo obtidos nas rendas mais altas.

Com relação à proxy utilizada para experiência, para a variável idade é observado um padrão de oscilação convexo, em $U$, conforme a magnitude de renda. Esta oscilação é heterogênea e inicia com coeficientes superiores nos quantis mais baixos, diminuindo nos quantis intermediários e retornando a ascender nos mais altos.

Conforme apresentado na revisão teórica, sobre a discriminação de gênero encontrada na literatura (SANBORN, 1964; COHEN, 1971; OAXACA, 1973; SCHWAAB; CERETTA; DUTRA, 2017), era aguardado que os homens recebessem mais do que as muIheres, como de fato identificou-se neste estudo. Deve-se salientar, todavia, a dimensão e magnitude da assimetria desse diferencial, conforme o nível de renda. Observando-se que, quanto maior o rendimento condicional, isto é, nos quantis mais altos, o efeito negativo de ser do gênero feminino no salário é superior. Isso revela a tendência de maior 
discriminação salarial por gênero nos níveis salariais mais elevados. Esse resultado pode estar atrelado a, segundo Flory, Leibbrandt e List (2010), as mulheres serem mais predispostas a se afastar de locais de trabalho competitivos, os quais apresentam, na maioria das vezes, maiores salários.

Destaca-se ainda sobre os resultados de gênero, analisando a Figura 1 juntamente com a Tabela 1, que a TCH não subsidia a explicação do diferencial salarial por gênero encontrado, pois as mulheres apresentam maior média de educação formal do que os homens. Ademais, adicionalmente a isso, dados do Inep (2016) afirmam que, dos concluintes do Ensino Supeior, $61 \%$ são do gênero feminino. Esse resultado instiga uma maior averiguação, pois no estudo seminal de Oaxaca (1973) a remuneração desigual por trabalho igual não foi a responsável por grande parte do diferencial salarial entre homens e mulheres nos Estados Unidos, e sim a concentração de mulheres em empregos de menor remuneração. Outros estudos explicam o diferencial salarial por gênero além das diferenças em capital humano e da discriminação, adicionando diferenças de gênero em competitividade (GNEEZY; NIEDERLE; RUSTICHINI, 2003; NIEDERLE; VESTERLUND, 2007; FLORY; LEIBBRANDT; LIST, 2010); e diferenças em negociações salariais (BABCOCK et al., 2006; SMALL et al., 2007; LEIBBRANT; LIST, 2012).

A dummy que identifica ser funcionário da esfera pública apresenta comportamento assimétrico positivo, sendo crescente ao longo dos quantis, isto é, o impacto de ser funcionário público eleva-se conforme se eleva a renda. Com relação aos resultados do funcionalismo público, alguns fatores merecem destaque, como a forma de ingresso por concurso público, no qual se selecionam os candidatos com melhor desempenho ou maiores níveis de conhecimentos (BRASIL, 1990).

Em síntese, observam-se coeficientes heterogêneos e ascendentes para todas as variáveis, isto é, quanto maior a renda, maiores são os impactos das variáveis, sejam eles positivos ou negativos. Assim sendo, para as maiores rendas ocorrem os maiores impactos positivos para cada ano adicional de escolaridade, assim como, de forma equivalente, para as menores rendas ocorrem os menores acréscimos para anos adicionais de estudo. De maneira análoga, nas maiores rendas ocorrem os maiores impactos negativos também, ou seja, os maiores níveis de discriminação de gênero e raciais.

\section{CONSIDERAÇÕES FINAIS}

O objetivo principal deste estudo foi mensurar os efeitos do capital humano sobre os salários do trabalhador na Região Sul do Brasil, tendo como proposta avaliar os impactos do capital humano na remuneração para diferentes quantis de renda, identificando, ainda, fatores discriminatórios. Para isso, utilizou-se um modelo de estimação de salários, baseado nos pressupostos mincerianos (MINCER, 1974) por meio do método de regressões quantílicas e a técnica de decomposição salarial de Oaxaca-Blinder (1973).

Os resultados das decomposições salariais indicam que, apesar do diferencial salarial médio ser maior entre raças no sul do Brasil, a discriminação por gênero é maior do que a racial. E observando os resultados da decomposição por setores, nota-se que, embora existam diferenças não explicadas, grande parte do hiato salarial entre os trabaIhadores públicos e privados é explicado por diferenças no efeito composição, isto é, em diferenças de acumulação de capital humano (estudo, experiência, etc.). 
Os principais resultados indicam que os impactos do capital humano, estimados neste estudo em escolaridade formal e experiência, são heterogêneos nos quantis. Os impactos advindos da escolaridade são superiores aos referentes à experiência, e têm seus efeitos majorados conforme se eleva a renda. Sendo assim, esse estudo aponta que os impactos da educação no salário/hora para a Região Sul do Brasil são heterogêneos e ascendentes a partir do segundo quantil de renda.

Referente à identificação de fatores discriminatórios, foram encontrados impactos negativos para as dummies de gênero e raça/cor, apresentando-se como determinantes redutores de renda. Os resultados sugerem que grande parte do diferencial do salário/ hora entre raças no sul do Brasil é devido a diferenças em capital humano, mas que uma parcela do hiato é devido a fatores inexplicados, sugerindo, ainda, haver o efeito glass ceiling para os não brancos, revelando semelhança aos estudos de âmbito nacional. O resultado que merece maior relevância, contudo, é quanto aos diferenciais de gênero, os quais mostraram-se contrários aos estudos internacionais e revelando uma particularidade do sul do Brasil, pois conforme se eleva a renda, maior é o hiato salarial entre homens e mulheres, chegando à magnitude de aproximadamente $30 \%$, sugerindo evidências para apenas o efeito glass ceiling no sul do Brasil.

Salienta-se que a participação das mulheres na força de trabalho tem aumentado de maneira quantitativa no país, em resposta a mudanças culturais e econômicas, com redução na desigualdade salarial (IBGE, 2017a). Conforme verificado, no entanto, a discriminação de gênero é uma constante no mercado de trabalho brasileiro. Os dados do Inep (2016) e desta pesquisa apontam que as mulheres apresentam nível educacional médio superior ao dos homens, o que teria como consequência ceteris paribus, melhores oportunidades de emprego e salários para elas, conforme preconiza a $\mathrm{TCH}$, entretanto isto não ocorre.

Os resultados deste estudo têm contribuição teórica na área de gestão de pessoas, adicionando resultados empíricos às questões de políticas salariais. Ainda, os resultados contribuem de forma prática em questões salariais, sendo informativa aos trabalhadores, proporcionando resultados sobre os retornos de se investir em educação. Espera-se, ainda, que este estudo contribuía para elaboração de políticas públicas buscando igualdade salarial no sul do Brasil, além de motivar políticas que possibilitem melhores condições no ensino para desenvolvimento da força de trabalho.

Cabe destacar que esta pesquisa apresentou alguns pontos de limitações, como informações de negociações salariais e questões referentes a características dos ambientes de trabalho quanto à competitividade. A base de dados da Pnadc, entretanto, não permite que se controle alguns aspectos como esses mencionados, constituindo essa uma lacuna existente neste trabalho. Como proposta para futuras pesquisas sugere-se realizar uma análise de forma segregada por gênero e raça/cor, identificando diferenças salariais pareadas por profissões, cargos de trabalho, níveis de escolaridade e agregando informações referentes ao ambiente de trabalho.

\section{REFERÊNCIAS}

ADIREKSOMBAT, K.; ZHENG, F.; SAKELLARIOU, C. The Evolution of Gender Wage Differentials and Discrimination in Thailand: 1991-2007. An Application of Unconditional Quantile Regression. Economic Growth Centre Working Paper Series 1005, Nanyang Technological University, School of Humanities and Social Sciences, Economic Growth Centre, 2010. 
ADNAN, W.; MIAARI, S. H. Voting patterns and the gender wage gap. Journal of Economic Behavior and Organization, v. 146, p. 222-247, 2018.

AGRAWAL, T. Gender and caste-based wage discrimination in India: some recent evidence. J Labour Market Res., v. 47, p. 329-340, 2014.

ALEJO, J.; GABRIELLI, M. F.; SOSA-ESCUDERO, W. The Distributive Effects of Education: An Unconditional Quantile Regression Approach. Revista de Análisis Económico, v. 29, n. 1, p. 53-76, 2014.

ALTONJI, J. G.; BLANK, R. M. "Race and Gender in the Labor Market." In: Handbook of Labor Economics, v. 3, edit. Orley Ashenfelter and David Card, p. 3.143-3.259. Amsterdam: Elsevier, 1999.

ASSIS, R. S.; ALVES, J. S. Hiato salarial entre homens e mulheres no Brasil segundo condição migratória: o mercado de trabalho é segregado ou discrimina? Revista Econômica do Nordeste, v. 45, n. 1, p. 120-135, 2014.

BABCOCK, L. et al. Gender differences in the propensity to initiate negotiations. In: CRÉMER, D. D.; ZEELENBERG, M.; MURNIGHAN, J. K. (org.). Social Psychology and Economics. Mahwah, NJ: Lawrence Erlbaum, 2006. p. 239-259.

BARROS, R. P. et al. Inserção no mercado de trabalho: diferenças por sexo e consequências sobre o bem-estar. Rio de Janeiro: Ipea, jun. 2001. (Texto para Discussão, n. 796).

BEAUVOIR, Simone de. 1908-1986. O segundo sexo. 2. ed. Tradução Sérgio Milliet. Rio de Janeiro: Nova Fronteira, 2009.

BECKER, G. S. Human capital: a theoretical and empirical analysis, with special reference to education. Chicago: The University of Chicago Press, 1964.

BECKER, G. The Economics of Discrimination. The University of Chicago Press, 1971.

BHORAT, H.; GOGA, S. The gender wage gap in post-apartheid South Africa: a re-examination. Journal of African Economies, v. 22, n. 5, 2013.

BLINDER, A. S. Wage discrimination: reduced form and strutural estimes. Journal of Human Resources, p. 436-455, 1973.

BRASIL. Lei n. 10.097, de 19 de dezembro de 2000. Altera dispositivos da Consolidação das Leis do TrabaIho - CLT. Disponível em: http://www.planalto.gov.br/ccivil_03/Leis/L10097.htm.

BRASIL, R. G.; MACEDO, J. J. Desigualdade de renda no Brasil: a influência do diferencial público-privado, aposentadorias e pensões. Revista de Econ. e Desenv., v. 29, n. 1, p. 610-627, 2017.

BRASIL. Lei no 7.716, de 5 de janeiro de 1989. Define os crimes resultantes de preconceito de raça ou de cor. Diário Oficial [da] República Federativa do Brasil, 5 de dezembro de 1989. Disponível em: http:// www.planalto.gov.br/ccivil_03/leis/L7716.htm. Acesso em: 29 mar. 2018.

BRASIL. Lei Federal no 8.112, de 11 de dezembro de 1990. Dispõe sobre o regime jurídico dos servidores públicos civis da União, das autarquias e das fundações públicas federais. Diário Oficial [da] República Federativa do Brasil, Brasília, DF, 11 de dezembro de 1990. Disponível em: https://www.planalto.gov.br/ ccivil_03/LEIS/L8112cons.htm. Acesso em: 30 mar. 2018.

BRASIL. Constituição Federal. Constituição da República Federativa do Brasil. Brasília, DF: Senado Federal: Centro Gráfico, 1988.

CACCIAMALI, M. C. S.; HIRATA, G. I. A influência da raça e do gênero nas oportunidades de obtenção de renda: uma análise da discriminação em mercados de trabalho distintos: Bahia e São Paulo. Estudos Econômicos, São Paulo, v. 35, n. 4, p. 767-795, out./dez. 2005.

CACCIAMALI, M. C. S.; TATEI, F.; ROSALINO, J. W. Estreitamento dos diferenciais de salários e aumento do grau de descriminação: limitações da mensuração padrão? Planejamento e Políticas Públicas, Brasília, $\mathrm{n}$. 33, p. 195-222, 2009.

CHI, W.; LI, B. Glass Ceiling or Sticky Floor? Examining the Gender earnings differential across the earnings distribution in urban China, 1987-2004. Journal of Comparative Economics, n. 36, p. 243-263, 2008.

CHI, W.; LI, B.; YU, Q. Decomposition of Changes in Earnings Inequality in China: A Distributional Approach. Unpublished. Munich Personal RePEc Archive. Paper n. 3.806, p. 1-34, 2007.

CIRINO, J. F.; DALBERTO, C. R. Trabalhadores formais versus informais: diferenças de rendimento para a região metropolitana de Belo Horizonte. Perspectiva Econômica, v. 2, nov. 2015.

COELHO, A. M.; CORSEUIL, C. H. Diferenciais salariais no Brasil: um breve panorama. Rio de Janeiro: Ipea, ago. 2002 (Texto para Discussão, n. 898).

COHEN, M. S. Sex Differences in Compensation. Journal of Human Resources, VI, p. 434-447, 1971.

COUCH, K.; DALY, M. C. Black-White Wage Inequality in the 1990s: A Decade of Progress. Economic Inquiry, 1, p. 31-41, 2002. 
CUGINI, S. C. B. et al. A força de trabalho feminina no mercado de trabalho brasileiro: discriminação salarial por gênero em 2002 e 2011. In: ENCONTRO DE ECONOMIA PARANAENSE, 11., 2014, Apucarana. Anais [...]. Apucarana: Unespar, 2014. 19p.

DOERINGER, P.; PIORE, M. Internal labor markets and manpower analysis. Washington, DC, US, May 1970. DUNCAN, O.; DUNCAN, B. A Methodological Analysis of Segregation Indexes. American Sociological Review, 20, p. 210-217, 1955.

FLORY, J.; LEIBBRANDT, A.; LIST, J. A. Do Competitive Work Places Deter Female Workers? A Large-scale Natural Field Experiment on Job-Entry Decisions. NBER Working Paper n. 16.546, 2010.

FRYER, R. Racial Inequality in the 21st Century: The Declining Significance of Discrimination. National Bureau of Economic Research, NBER Working Paper n. 16.256, 2010.

FUCHS, V. R. Differences in Hourly Earnings Between Men and Women. Monthly Labor Review, XCIV, p. 9-15, 1971.

GNEEZY, U.; NIEDERLE, M.; RUSTICHINI, A. Performance in Competitive Environments: Gender Differences. Quarterly Journal of Economics, 118(3), p. 1.049-1.074, 2003.

GOMES, M. R.; SOUZA, S. de C. I. Desigualdades salariais de gênero no primeiro emprego, reemprego e remanescentes nos setores econômicos: evidências para o Sul do Brasil. Análise Econômica, Porto Alegre, v. 36, n. 71, p. 101-134, set. 2018.

GUIMARÃES, C. R. F. F.; SILVA, G. Pay gap by gender in the tourism industry of Brazil. Tourism Management, v. 52, p. 440-450, 2016.

HARA, $H$. The gender wage gap across the wage distribution in Japan: Within- and between-establishment effects. Labour Economics, v. 53, p. 213-229, Apr. 2018.

HECKMAN, J. Sample selection bias as a specification error. Econometrica, v. 47, p. 153-161, 1979.

IBGE. Instituto Brasileiro de Geografia e Estatística. Pesquisa por amostra de domicilios contínua trimestral, 2017a. Disponível em: https://sidra.ibge.gov.br. Acesso em: 26 fev. 2018.

IBGE. Instituto Brasileiro de Geografia e Estatística. Sistema de Contas Regionais: Brasil 2015. Contas Nacionais, n. 57, ISSN 1415-9813, 2017b.

INEP. Instituto Nacional de Estudos e Pesquisas Educacionais Anísio Teixeira. Sinopse estatística da educação superior 2015, 2016. Disponível em: http://portal.inep.gov.br/sinopses-estatisticas-da-educacao-superior. Acesso em: 26 fev. 2018.

JANN, B. The Blinder-Oaxaca decomposition for linear regression models. The Stata Journal, v. 8, n. 4, p. 453-479, May 2008.

JOHNSTON, J.; DINARDO, J. Econometric Methods. 4. ed. New York: McGraw Hill, 1996.

JUNG, S. E.; CHOE, C.; OAXACA, R. L. Gender wage gaps and risky vs. secure employment: An experimental analysis. Labour Economics, v. 52, p. 112-121, Apr. 2018.

KOENKER, R.; BASSETT JR., G. Regression quantiles. Econometrica, p. 33-50, 1978.

LANG, K.; LEHMANN, J.; YEON, K. Racial discrimination in the labor market: Theory and empirics. Journal of Economic Literature, 4, p. 959-1.006, 2012.

LEIBBRANDT, A.; LIST, J. A. Do women avoid salary negotiations? Evidence from a large scale natural field experiment. NBER Working Paper $\mathrm{n}$ ㅇ 18.511, 2012.

LEITE, P. G. Race discrimination or inequality of opportunities: The Brazilian case. In: Poverty, inequality, and policy in Latin America. Ibero America Institute for Economic Research, CESifo seminar series, 2005. p. 85-126.

LEUZE, K.; STRAUSS, S. Why do occupations dominated by women pay less? How 'female-typical' work tasks and working-time arrangements affect the gender wage gap among higher education graduates. Work, Employment and Society, v. 30, n. 5, p. 802-820, 2016.

LIPS, H. M. Acknowledging Discrimination as a Key to the Gender Pay Gap. Sex Roles, v. 68, n. 3-4, p. 223230, 2013.

LLAMAS, V. R.; LÓPEZ, R. A. Capital humano y diferencias salariales en México, 2000-2009. Estudios Fronterizos, Nueva Época, v. 13, n. 26, p. 175-200, 2012.

MEDEIROS, M.; SOUZA, P. H. The State and income inequality in Brazil. Social Science Research Network (SSRN), paper n. 2.257.857, p. 1-34, 2014.

MINCER, J. Schooling, experience and earnings. Columbia: Columbia University Press, 1974.

NEUMARK, D. Employers Discriminatory Behaviour and the Estimation of Wage Discrimination. Journal of Human Resources, vol. 23, n. 3, 1988.

NIEDERLE, M.; VESTERLUND, L. Do Women Shy Away From Competition? Do Men Compete Too Much? Quarterly Journal of Economics, 122(3), p. 1.067-1.101, 2007. 
OAXACA, R. Male-female wage differentials in urban labor markets. International Economic Review, p. 693-709, 1973.

OAXACA, R.; RANSOM, M. R. On discrimination and the decomposition of wage differentials. Jornal of Econometrics, v. 61, n. 1, p. 5-21, 1994.

PEREIRA, R. M.; OLIVEIRA, C. A. Os diferenciais de salário por gênero no Rio Grande do Sul: uma aplicação do modelo de Heckman e da decomposição de Oaxaca-Blinder. Redes: Revista do Desenvolvimento Regional, Santa Cruz do Sul, RS, v. 21, n. 1, p. 148-173, 2016.

PHELPS, E. S. The statistical theory of racism and sexism. The American Economic Review, v. 62, n. 4, p. 659-661, Sept. 1972.

PNUD. Programa das Nações Unidas para o Desenvolvimento. In: INSTITUTO DE PESQUISA ECONÔMICA APLICADA E FUNDAÇÃO JOÃO PINHEIRO. Atlas do Desenvolvimento Humano no Brasil, 2015. Disponível em: http://www.atlasbrasil.org.br. Acesso em: 5 jan. 2018.

SALARDI, P. An Analysis of Pay and Occupational Differences by Gender and Race in Brazil - 1987 to 2006. Unpublished. PhD Thesis, University of Sussex, U.K, 2013.

SALARDI, P. The evolution of Gender and Racial Occupational Segregation Across Formal and Non-formal Labor Markets in Brazil, 1987 to 2006. The Review of Income and Wealth, v. 62, n. 1, p. s68-s89, 2014.

SANBORN, H. Pay Differences Between Men and Women. Industrial and Labor Relations Review, p. 534550, 1964.

SCHULTZ, T. W. O valor econômico da educação. Trad. P. Werneck. Rio de Janeiro: Zahar, 1967.

SCHWAAB, K. S.; CERETTA, P. S.; DUTRA, V. Efeitos da educação na renda. In: SEMEAD - SEMINÁRIOS EM ADMINISTRAÇÃO, 20., 2017, São Paulo. Anais [...]. São Paulo: USP, nov. 2017.

SMALL, D. A. et al. Who goes to the bargaining table? The influence of gender and framing on the initiation of negotiation. Journal of Personality and Social Psychology, 93 (4), p. 600-613, 2007.

SOUZA, S. D. C. I.; GOMES, M. R. Diferenças salariais de gênero no primeiro emprego dos trabalhadores: análise no estado da Bahia em 2013. In: ENCONTRO DE ECONOMIA BAIANA, 9., 2015, Salvador. Anais [...]. Salvador: Fieb, 2015. 19p.

WORLD ECONOMIC FORUM'S. The global gender gap report 2018. Disponível em: http://www3.weforum. org/docs/WEF_GGGR_2018.pdf. Acesso em: 7 jul. 2019. 


\section{ANEXO 1}

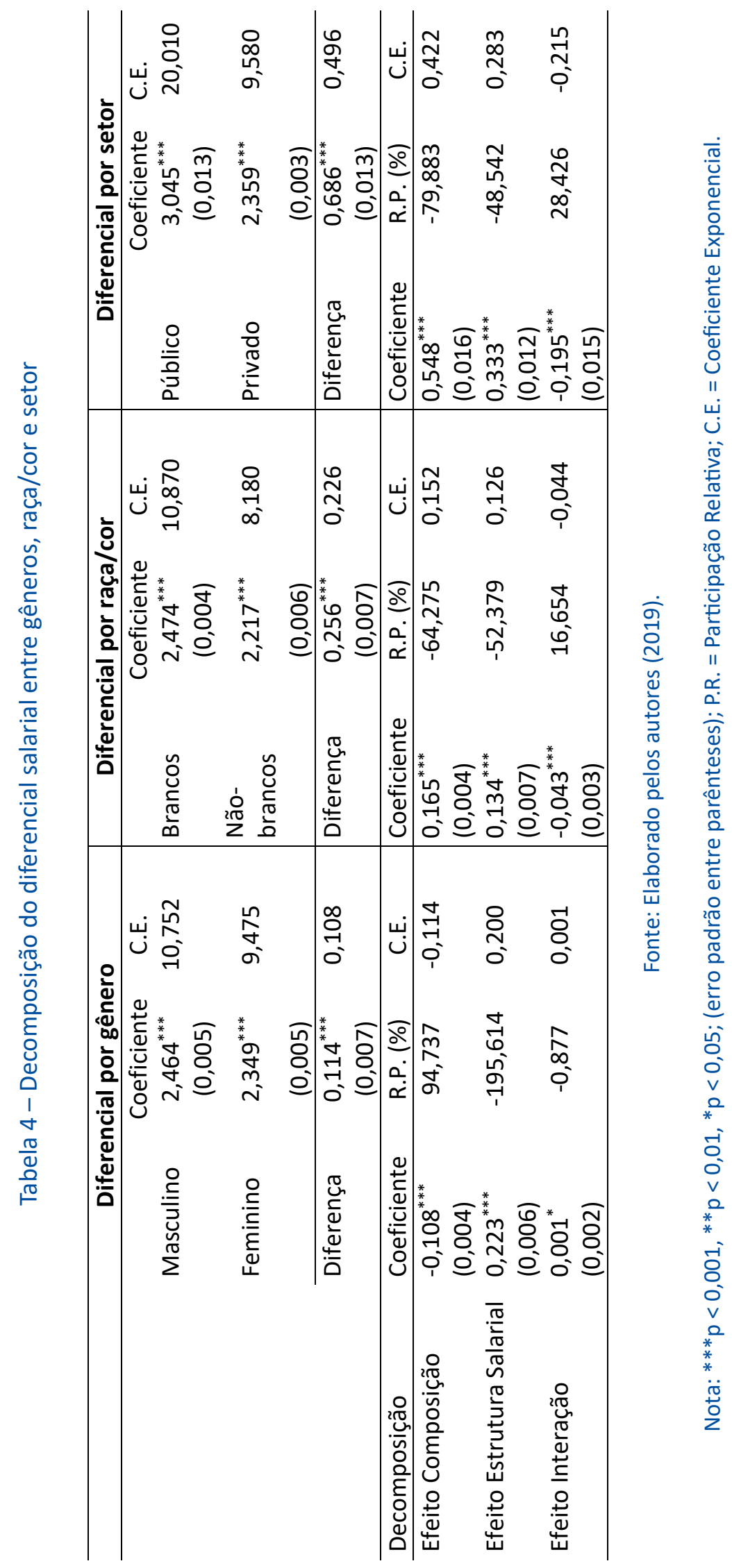




\section{ANEXO 2}

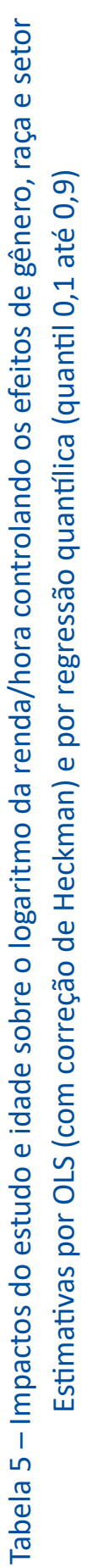

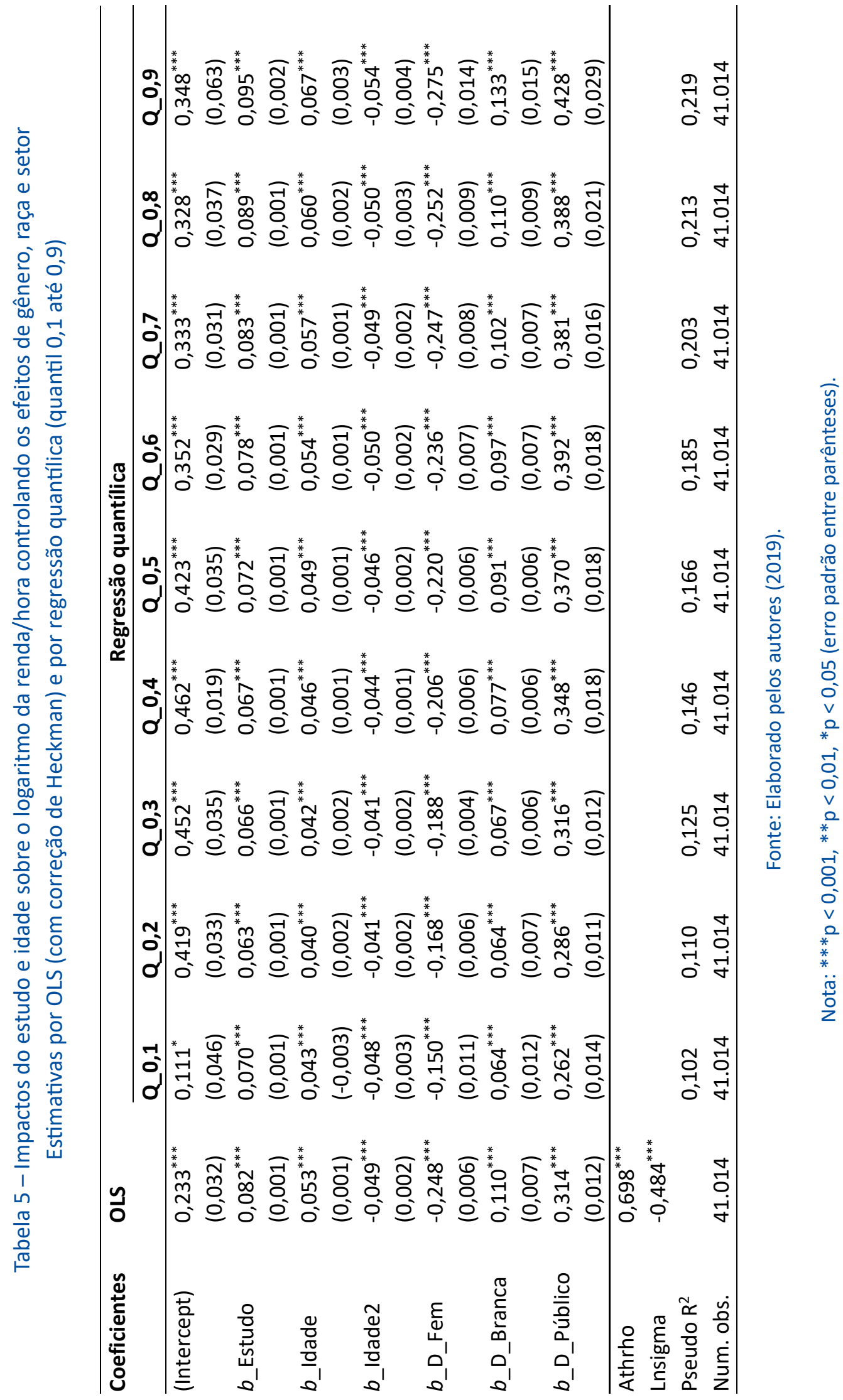

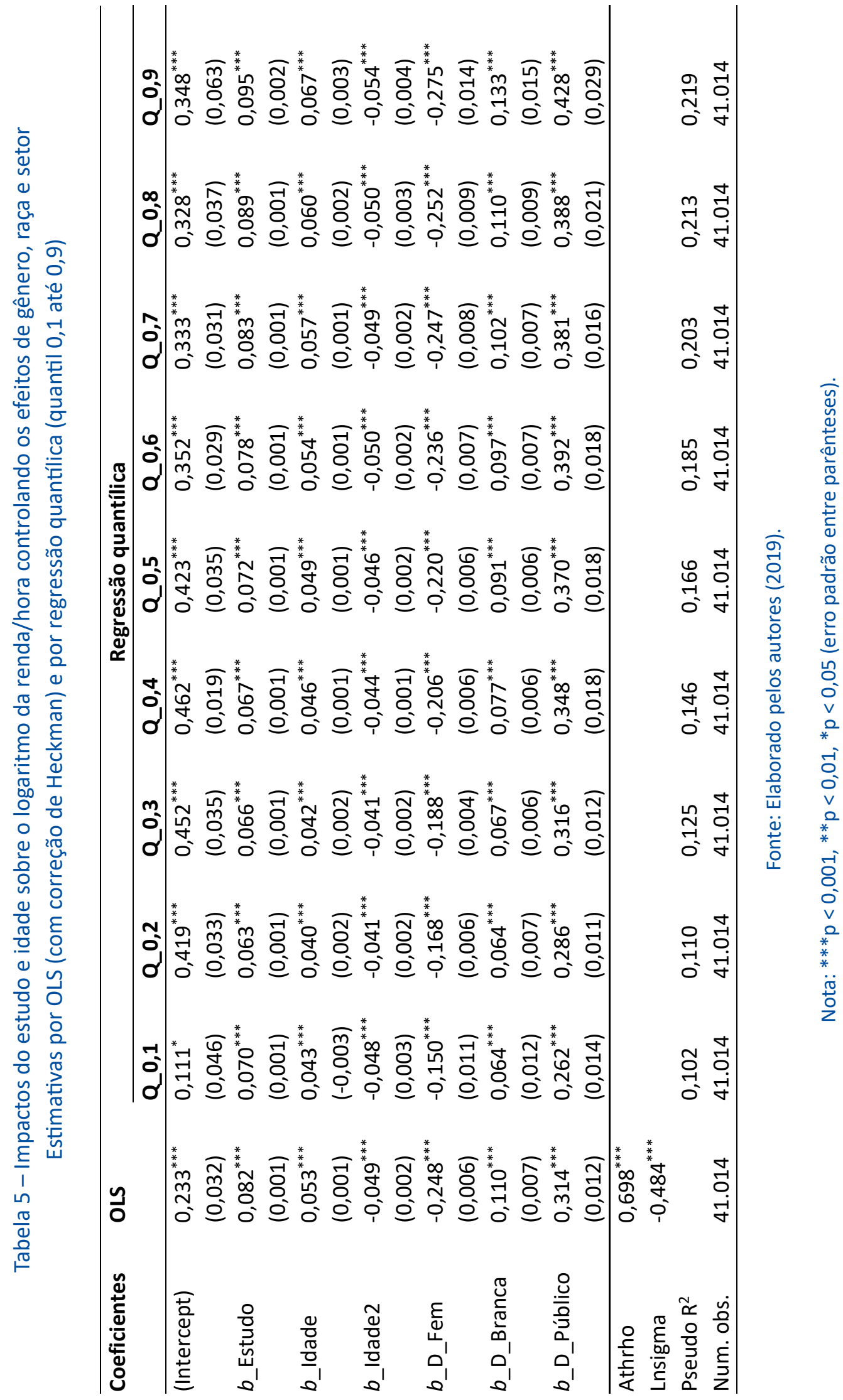

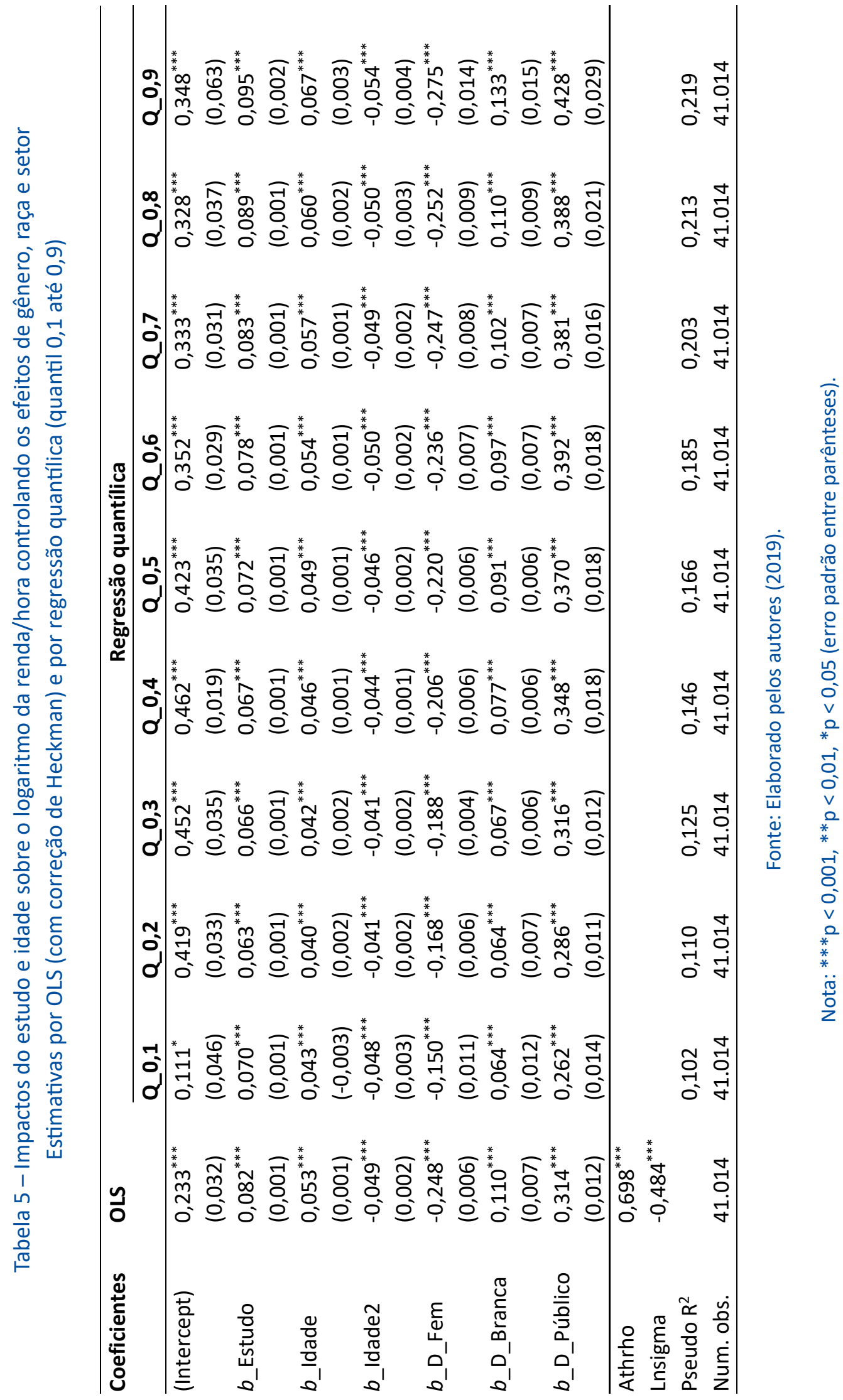

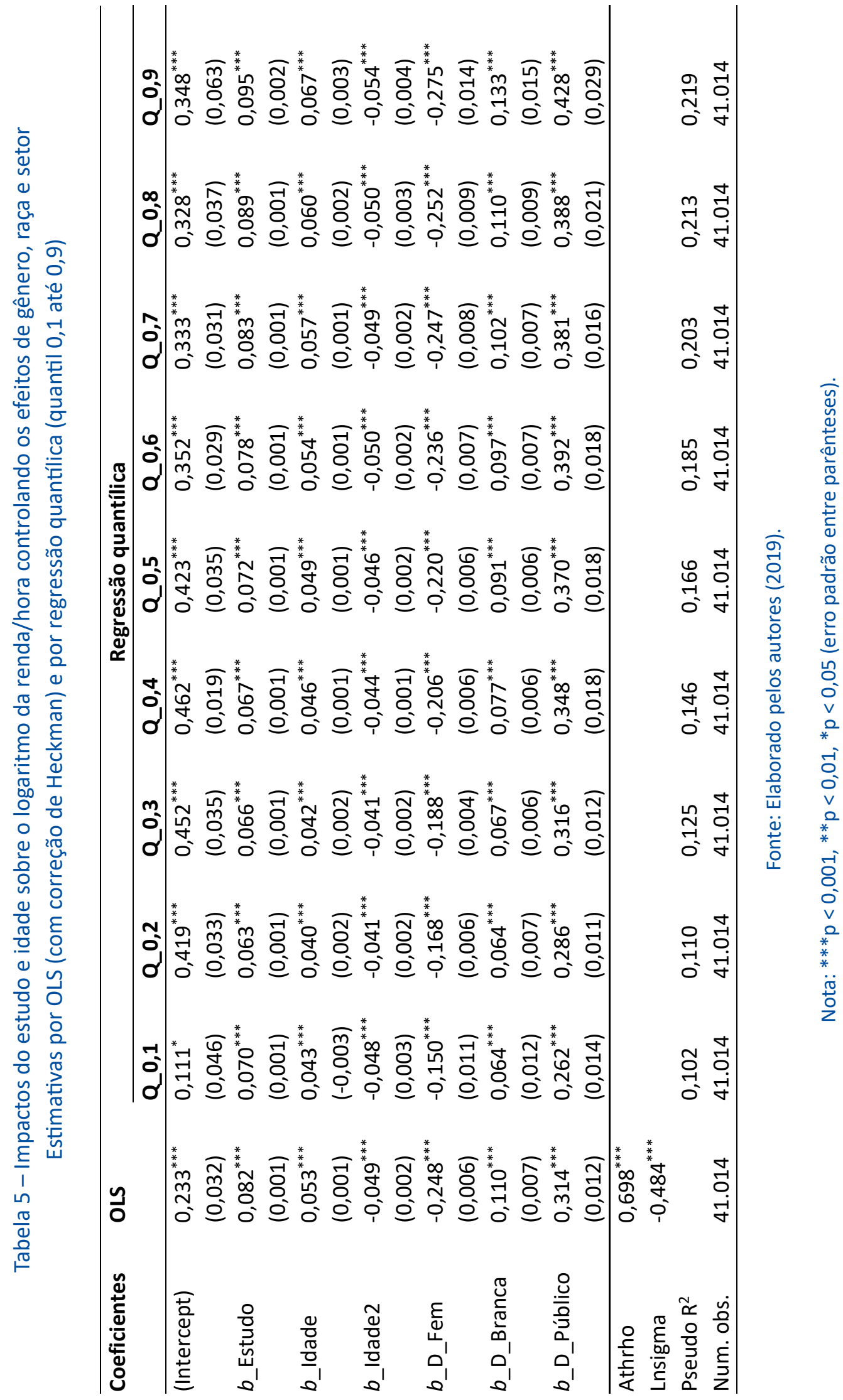

